\title{
Not a chance
}

\section{It just doesn't add up.}

\section{Peter Haff}

We have been together a long time, and I have got to know my student well. I would like to be doing other things, but the problem he came to discuss won't let us go. Roscoe had been a student in my introductory physics class when, a number of years ago, he appeared uninvited at my office door.

"It's about mathematics," he began without prologue.

I pondered the bearded young man a moment, then took off my glasses and began polishing them. "I am happy to talk about mathematics," I began, "but you realize I'm not a mathematician ..."

"Well, it's also about physics," he interrupted, and sat down without invitation in the hard-backed seat that faced my desk.

I leaned back in my swivel chair and looked at him. This is going to take a while, I thought. How true that would be I had no idea. I put my glasses back on.

"It started when I heard about the proof of the four-colour theorem."

I nodded. "Only four colours are needed to distinguish between any arrangement of countries on a two-dimensional map."

"Yes, but the problem is, we don't really know if the proof is right." Roscoe looked at me carefully.

I picked up a pencil and twiddled it between my fingers. I knew that very long computer proofs, like that first used several decades ago in proving the fourcolour theorem, are controversial in the mathematics community. It is difficult for any one person to be sure that every line of code is correct.

"The mathematicians seem to have come to a consensus that there are no mistakes in the proof," I remarked mildly.

"Consensus!" he blurted out. "Consensus can't reduce the probability of a theorem being wrong to zero!"

Roscoe's face had turned red and he was leaning towards me at an alarming angle. I swivelled slightly in my chair.

"I see your point," I remarked carefully, "but..."

I stopped swivelling and waited.

"There is always a non-zero probability of a making a physical mistake," he continued. "That's why it's a matter of physics. Maybe the mathematician misreads a comma. She wrongly concludes the proof is correct."

I started to swivel back and forth again. "But many smart mathematicians have combed through the proof in detail, so the chances that..." I stopped.

Roscoe beamed as if he had just caught a schoolboy in an elementary mistake. "Exactly! It's a matter of chance. The chances are small that the proof is wrong, but not zero!"

I rocked more slowly in my chair.

"But look," I finally said, somewhat defensively, "let's say that the proof is wrong, which it probably...” I looked a little guilty “... isn't. It doesn't really matter much does it? After all, before the proof was published no one knew whether it was true or not."

Roscoe looked at me as if I were an imbecile. "But surely you see the implication, professor?" he asked.

I looked puzzled.

"Let's say the probability of error in the four-colour theorem proof is $P$. But now consider another theorem whose proof is just half as long. The chances of error are less than $P$ in that case, but certainly not zero. Now by induction," he continued ...

I stopped swivelling. Roscoe leaned even further towards me.

"So let's consider a 100-line proof, a 10-line proof, a 2-line proof. Every line has some chance, however small, of being wrong. If a mathematician can make a physical mistake once - of perception, of memory, of whatever mental processes enable him to conclude the validity of one line of code, of one step in a proof, then he can make a mistake again ... and again."

As if anticipating my objections, he interrupted himself. "And because it's a matter of physics, there are consequences, professor."

I don't know if what he did next was deliberate, or whether he just slipped.

Roscoe had tilted completely out of his chair, falling face first, in slow motion. Before I recovered my surprise he was halfway to the floor.

He continued his line of argument. "If a mathematician can make one mistake, then he can make the same mistake twice, or make another mistake on another line. A second mathematician also faces a similar chance of error, so does a third ..."

I was transfixed by the impending collision of Roscoe with the floor, but somehow felt far away, as if I could do nothing about it.
"So your argument is that there is some probability that mathematics itself is wrong?"

"Yes! Not just the fourcolour theorem, but the most elementary proof could be in error."

Roscoe was three-quarters of the way to the floor. I could see only the back of his head.

"What other sort of proof could be wrong?"

"Well, maybe Euclid's proof that there is an infinite number of primes is wrong."

For some reason I was reminded of Wigner's observation on the uncanny ability of mathematics to mimic the physical world. What would it mean for physics if there was a Eureka moment when someone finally realized that mathematics was wrong?

I pondered Roscoe's argument. My pencil twiddled more slowly between my fingers.

He continued: "Perhaps there is something fundamentally wrong with summing an infinite series. Maybe all those limits when infinitesimals are supposed to go to zero don't really exist. Or maybe..."

I stared at the receding Roscoe whose face was now just inches from the floor. My pencil had stopped twiddling. "Maybe what?"

My chair was now still. I didn't blink. I didn't move.

"Or maybe Zeno was right," Roscoe said.

He was very close to the floor.

Peter Haff, a geologist at Duke University is currently studying the emergence of technology as a geological process in the evolution of Earth. 